\title{
INFLUENCES ON STUDENT CHOICE OF UNIVERSITY: EVIDENCE FROM VIETNAM
}

\author{
BUI HUY KHOI ${ }^{1}$, MOSES OLABHELE ESANGBEDO ${ }^{2}$ \\ ${ }^{1}$ Faculty of Business Administration, Industrial University of Ho Chi Minh City \\ ${ }^{2}$ Northwestern Polytechnical University, School of Management, Xi'an, China \\ buihuykhoi@iuh.edu.vn,moses@nwpu.edu.cn
}

\begin{abstract}
The purpose of this study was to identify the factors that influenced university choice in Vietnam. Survey data was collected from 167 students studying in Industrial University of HCM City, Vietnam. The research model was proposed from the study of university choice in the context of education in Vietnam. The reliability and validity of the scale were tested by Cronbach's Alpha, Average Variance Extracted $(\mathrm{Pvc})$ and Composite Reliability $(\mathrm{Pc})$. The analysis results of structural equation model (SEM) showed that the tested relationship between university choice and the four components of the University Choice included University Advertising, Student Expectation, Reference (Family and Friend) and University Reputation. Student Ability, University Characteristics and Enroll to university were not influenced University Choice of Student.
\end{abstract}

Keywords. Vietnam, university choice, Pc, Pvc, SEM, Smartpls 3.0

\section{INTRODUCTION}

In the past, the national university entrance examination was the only option if high school students in Vietnam wanted to pursue higher education [1]. Students who earned high scores entered prestigious universities, others entered lower-level universities or vocational colleges, whilst many other students would decide to wait another year and prepare for the following examination. From a higher education marketing perspective, this trend had developed new segments of prospective students whose choice behaviour, including the factors students consider when selecting universities and their information search process, differed from that in their market segments, and thus required a revised understanding of student choice behaviours [1]. Education is one of the important factors that contribute to achieving a goal of becoming a developed nation [2]. The parents expressed a strong attachment to the importance of educational qualifications for their children [3]. The decision of the students to continue their studies at the desired place of field of study plays an important role for their future success. If reality does not match to what is expected then the success will go under uncertainty. The act of choosing a university has many dimensions and impacts, which is part of a resolution effort as well as part of the decision-making process. The intense competition makes every university aware of a need to fully exploit its assets to maximize performance and to develop competitive advantage. One way to achieve this is to develop a university name so that it has a good reputation in the people's eyes and builds a trust [4] to lead to university choice of student. The purpose of this study was to identify the factors that influenced university choice in the context of education in Vietnam.

\section{REVIEW OF LITERATURE}

There were researches about university choice of student such as:

Firstly, the study of Rachmadhani et al (2018) indicated the higher competition in the context of the commercialization of higher education among State University and Private University in Indonesia. It becomes a threat and challenge faced by State University in recruiting new students. A clearer understanding of why and how students choose universities was needed to develop the brand awareness enhancement strategies of State University. This paper aimed to identify the factors that influence student's decision of university choice. The combination of HEdPERF dimensions and brand awareness 
indicators were used to develop the variables. These findings resulted that there were six factors in choosing higher education, including academics, facilities, campus life, reputation, industry linkage and access [5].

Secondly, the main purpose of Husain et al (2018) was to determine the factors that affecting students 'preference towards university and to focus on the essential factors in making it more attractive to students; thus attracting higher enrolment. The authors found there was a positive relationship between financial, quality, people, employability and student's preference towards university. Based on the results, authorities should seek for improvement of the whole aspect includes the quality, physical aspects, facilities, resources that provided to students. Previous researches examined factors towards students' preferences from various settings. However this research only focused on four factors namely quality, financial, employability and significant people to determine which factor are most contribute to students' preference [2].

Thirdly, the study of Le (2018) concluded university choice was a high-risk decision for prospective students, which required substantial effort to evaluate a range of choice factors. Understanding this complex process was a crucial task for marketers in the higher education sector, especially understanding the differences across market segments. Le's study analyzed the importance of choice factors, and the usage of information sources. Different from previous studies which collected data in the countries of destination, this study employed a data sample of prospective students from the country of origin of Vietnam. The findings provided insight into the key choice factors and information sources by market segment, with implications for the targeted marketing strategies of higher education providers discussed [1].

Fourthly, the paper of Iacopini and Hayden (2017) reported on the ways in which a selected group of parents in Vietnam decided which university one of their children should attend. Drawing upon narrative accounts provided by 16 parents of recent graduates from three universities in Hanoi, the paper sought to elucidate the kinds of considerations taken into account by parents in their decision-making and the nature of the parent-child relationships that were evident in the process. The paper presented a classification of parent-child relationships concerning the matter of university choice in Vietnam [3].

Fifthly, the research of Ming (2010) developed a conceptual framework to explore the institution factors that influence students' college choice decision in Malaysia. The independent variables that had been identified to have influenced of students' college choice decision are location, academic programme, college reputation, educational facilities, cost, availability of financial aid, employment opportunities, advertising, Higher Education Institutions (HEIs), representatives and campus visit [6].

Finally, the research of Chapman indicated a model of the influences affecting prospective students college choice. The influence of factors gave the tightening of institutional budgets, college admissions officers expect students to enroll. The focus in this stage is on the decision whether prospective students should pursue tertiary study. A prospective university student may spend a long time in the need recognition stage before making a decision. For example, for high school students considering entering a university upon graduation, the decision to study at a higher education institution may coincide with their high school studies. The length of this consideration period and difficulty in assessing are significant reasons why this stage is the most difficult to research [7].

Choice university could be defined as the criteria prospective students use for evaluating the available options [8]. When buying a product or service, the consumers would appraise the product attributes, such as quality, price, feature, or style. When considering a university, prospective students might take into account the ranking of university, tuition fee, or distance from home. Such choice factors were mostly considered by prospective students in the stages of information search and evaluation of alternatives. During these stages, prospective students sought information regarding these factors to reduce the uncertainty and risks associated with the decision [9]. In this research area, there are three variables frequently mentioned: course, location and reputation [10]. As the present study was conducted from the 
marketing perspective, the factors in this paper are related to the decision on which university to apply, not the decision on why to pursue higher education.

From a comprehensive review of prior research in this area, the present study adapted Hemsley-Brown and Oplatka [11]'s framework of the factors of university choice. As the present study included a segmentation analysis which explored the choice factors across demographic segments, the profile of students is not included in the list of choice factors, so that the categories of demographics and student academic in the review by Hemsley-Brown and Oplatka[11] were removed.

In summary, there were many factors on student university choice. In this paper, we designed a empirical study in the context of education in Vietnam to examine factors on university choice decision of student as figure 1 .

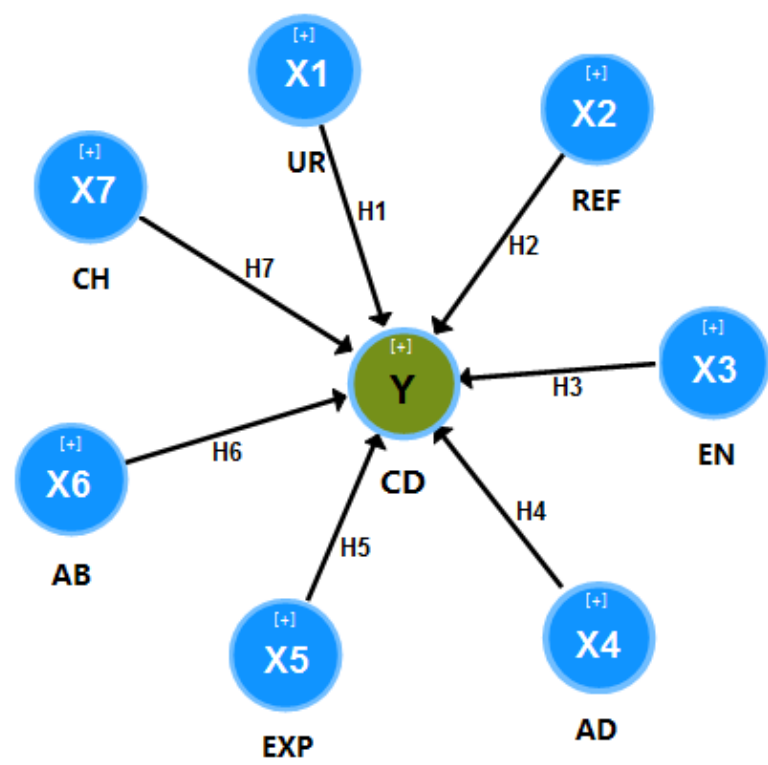

Code: UR(X1): University Reputation, REF(X2): Reference (Family and Friend), EN(X3): Enroll to university, AD(X4): University Advertising, EXP(X5): Student Expectation, AB(X6): Student Ability, CH(X7): University Characteristics, $\mathbf{C D}(\mathbf{Y})$ : University Choice Decision

Figure 1. The theoretical model

"Hypothesis 1 (H1). There was a positive impact of $\mathbf{U R}(\mathbf{X 1 )}$ : University Reputation and $\mathbf{C D}(\mathbf{Y})$ : University Choice Decision"

"Hypothesis 2 (H2). There was a positive impact of $\mathbf{R E F}(\mathbf{X} 2)$ : Reference and $\mathbf{C D}(\mathbf{Y})$ : University Choice Decision"

"Hypothesis 3 (H3). There was a positive impact of $\mathbf{E N}(\mathbf{X 3})$ : Enroll to university and $\mathbf{C D}(\mathbf{Y})$ : University Choice Decision"

"Hypothesis 4 (H4). There was a positive impact of $\mathbf{A D}(\mathbf{X 4 )}$ : University Advertising and $\mathbf{C D}(\mathbf{Y})$ : University Choice Decision"

"Hypothesis 5 (H5). There was a positive impact of $\mathbf{E X P ( X 5 ) : ~ S t u d e n t ~ E x p e c t a t i o n ~ a n d ~ R ~ C D ( Y ) : ~}$ University Choice Decision"

"Hypothesis 6 (H6). There was a positive impact of $\mathbf{A B}(\mathbf{X 6})$ : Student Ability and $\mathbf{C D}(\mathbf{Y})$ : University Choice Decision"

"Hypothesis 7 (H7). There was a positive impact of $\mathbf{C H}(\mathbf{X 7 )}$ : University Characteristics and $\mathbf{C D}(\mathbf{Y})$ : University Choice Decision"

\section{RESEARCH DESIGN AND METHODS}




\subsection{The research approach}

This survey sample allowed for the examination of university choice factors as the consumer was experiencing the decision-making process to select a university, rather than relying on the recall of first-year students, allowing for more accurate and reliable data.

An overview of the research methods used to collect and analyze the data was briefly discussed. In this research, a survey with questionnaire was used to collect data. The questionnaire was made in English and then translated into Vietnamese because all of respondents were Vietnamese. Research methodology was implemented through two steps: qualitative research and quantitative research. Qualitative research was conducted with a sample of 11 people. We divided into two groups to discuss about observations and variables and adjusted them to be suitable in the context of education in Vietnam. First group was from Industrial University of HCM City. They were first year students in business administration field. They had knowledge in university choice. This group used bilateral discussion within 30 minutes/person. Second group was experts coming from Industrial University of HCM City. There were two economic, an educational and a management specialists (1 professor, $3 \mathrm{PhD})$ within 60 minutes/person.

\subsection{Sample and Data collection}

The survey was conducted in Ho Chi Minh City, the largest city and a dynamic economic hub in Vietnam. With the support of and reference from Industrial University of HCM City, Vietnam.

Quantitative research had two periods. First period 1 was tested on a small sample to discover the flaws of the questionnaire. Second period of the official research was carried out as soon as the question was edited from the test results. Respondents were selected by convenient methods with a sample size of 167 students studying in Industrial University of HCM City. The questionnaire answered by respondents was the main tool to collect data. The questionnaire contained questions about their sex, field and training system. The survey was conducted in 2017,2018 . The questionnaire answered by respondents is the main tool to collect data. The questionnaire contained questions about the position of the factors that influenced university choice in Vietnam. A Likert-scale type questionnaire was used to detect those factors measured from (1) "strongly disagree" to (5) "strongly agree".

\subsection{Blinding}

All study personnel and participants were blinded to treatment for the duration of the study. No people had any contact with study participants.

\subsection{Datasets}

We validate our model on two standard datasets for relationship between university choice in Vietnam: SPSS.sav and Smartpls.splsm. Dataset has eight variables: seven independent variables and one variable. There are 167 observations and 31 items in dataset. SPSS.sav were used for descriptive statistics and Smartpls.splsm for advanced analysis.

\subsection{Data analysis}

Data processing and statistical analysis software is used by Smartpls 3.0 Software developed by SmartPLS GmbH Company in Germany. The reliability and validity of the scale were tested by Cronbach's Alpha, Average Variance Extracted (Pvc) and Composite Reliability (Pc). Followed by a structural equation model SEM was used to test the research hypotheses. Cronbach's alpha coefficient greater than 0.6 would ensure the scale reliability [12-14]. Composite Reliability (Pc) is better than 0.6 and Average Variance Extracted and rho_A must be greater than 0.5 [13-20]. Structural Equation Modeling (SEM) is used on the theoretical framework. Partial Least Square method can handle many independent variables, even when multicollinearity exists. PLS can be implemented as a regression model, predicting one or more dependent variables from a set of one or more independent variables or it can be implemented as a path model. Partial Least Square (PLS) method can associate with the set of independent variables to multiple dependent variables [13-17, 20]. 


\section{RESULTS}

\subsection{Reliability and validity}

Measurement model analyzed the data reliability and validity. The Cronbach criteria, composite reliability and average variance criteria had been used to validate the data internal reliability. On the other hand, Heterotrait-Monotrait ratio of correlations (HTMT) was employed to validate the data validity. However, according Hair Jr et al $[19,21]$ Cronbach alpha and composite reliability values should be more than 0.60 and AVE values should be more than 0.50 for the validation of construct reliability. On the other hand, in terms of construct validity according to Hair Jr et al [19, 21], HTMT values should be less than 1.0. The present found that all construct values were less than threshold values. The result of constructs reliability and validity can be seen in Table 1 and Table 2. Furthermore, the values of AVE can be seen in table 1.

Table 1. Construct reliability results

\begin{tabular}{|c|c|c|c|c|}
\hline Construct & Cronbach's Alpha & rho_A & $\begin{array}{c}\text { Composite } \\
\text { Reliability (Pc) }\end{array}$ & $\begin{array}{c}\text { Average } \\
\text { Variance } \\
\text { Extracted } \\
\text { (Pvc) } \\
\end{array}$ \\
\hline $\mathbf{A B}$ & 0.467 & 0.489 & 0.711 & 0.386 \\
\hline AD & 0.745 & 0.764 & 0.837 & 0.562 \\
\hline CD & 0.739 & 0.756 & 0.852 & 0.657 \\
\hline CH & 0.808 & 0.862 & 0.872 & 0.588 \\
\hline EN & 0.731 & 0.774 & 0.846 & 0.650 \\
\hline EXP & 0.706 & 0.743 & 0.817 & 0.530 \\
\hline REF & 0.668 & 0.684 & 0.794 & 0.491 \\
\hline UR & 0.643 & 0.681 & 0.784 & 0.483 \\
\hline
\end{tabular}

$$
\alpha=\frac{k}{k-1}\left[1-\frac{\sum \sigma^{2}\left(x_{i}\right)}{\sigma_{x}^{2}}\right] \quad \rho_{c}=\frac{\left(\sum_{i=1}^{p} \lambda_{i}\right)^{2}}{\left(\sum_{i=1}^{p} \lambda_{i}\right)^{2}+\sum_{i=1}^{p}\left(1-\lambda_{i}{ }^{2}\right)} \quad \rho_{v c}=\frac{\sum_{i=1}^{p} \lambda_{i}{ }^{2}}{\sum_{i=1}^{p} \lambda_{i}{ }^{2}+\sum_{i=1}^{p}\left(1-\lambda_{i}{ }^{2}\right)}
$$

$\mathrm{k}$ : factor, xi: observations, $\lambda_{\mathrm{i}}$ is a normalized weight of observation variable, $\sigma^{2}$ : Square of Variance, $\mathrm{i} ; 1-\lambda i^{2}-$ the variance of the observed variable i. UR: University Reputation, REF: Reference (Family and Friend), EN: Enroll to university, AD: University Advertising, EXP: Student Expectation, AB: Student Ability, CH: University Characteristics, $\boldsymbol{C D}$ : University Choice Decision

Table 1 showed that composite reliability varied from 0.711 to 0.853 , Cronbach's alpha from 0.643 to 0.808, Average Variance Extracted from 0.530 to 0.657 and rho_A from 0.681 to 0.862 which were above preferred value of 0.5 . This proved that model was internally consistent. To check whether the indicators for variables display convergent validity, Cronbach's alpha were used. From table 1, it could be observed that all the factors were reliable $(>0.60)$ and Pvc, rho_A $>0.5$ [15]. Factor AB had Pvc, rho_A $<0.5$ and Cronbach's alpha $<0.6$.

Factor REF and UR had Pvc $<0.5$. They were unaccepted but we would continue them in SEM.

Table 2. Constructs validity results (HTMT: Fornell-Larcker Criterion)

\begin{tabular}{lllllllll}
\hline Construct & AB & AD & CD & CH & EN & EXP & REF & UR \\
AB & 0.621 & & & & & & & \\
AD & 0.162 & 0.750 & & & & & \\
CD & 0.436 & 0.317 & 0.811 & & & & \\
CH & 0.067 & 0.274 & 0.226 & 0.767 & & & & \\
EN & 0.011 & 0.503 & 0.138 & 0.319 & 0.806 & & & \\
\hline
\end{tabular}




\begin{tabular}{lllllllll} 
EXP & 0.343 & 0.327 & 0.609 & 0.193 & 0.150 & 0.728 & & \\
REF & 0.193 & 0.073 & 0.311 & 0.084 & 0.070 & 0.171 & 0.701 & \\
UR & 0.461 & 0.216 & 0.603 & 0.231 & 0.237 & 0.541 & 0.306 & 0.695 \\
\hline
\end{tabular}

UR: University Reputation, REF : Reference (Family and Friend), EN: Enroll to university, AD: University Advertising, EXP: Student Expectation, AB: Student Ability, CH: University Characteristics, CD: University Choice Decision

\subsection{Structural Equation Modeling (SEM)}

Structural Equation Modeling (SEM) was used on the theoretical framework. Partial Least Square method could handle many independent variables, even when multicollinearity exists. PLS could be implemented as a regression model, predicting one or more dependent variables from a set of one or more independent variables or it could be implemented as a path model. Partial Least Square (PLS) method could associate with the set of independent variables to multiple dependent variables [15].

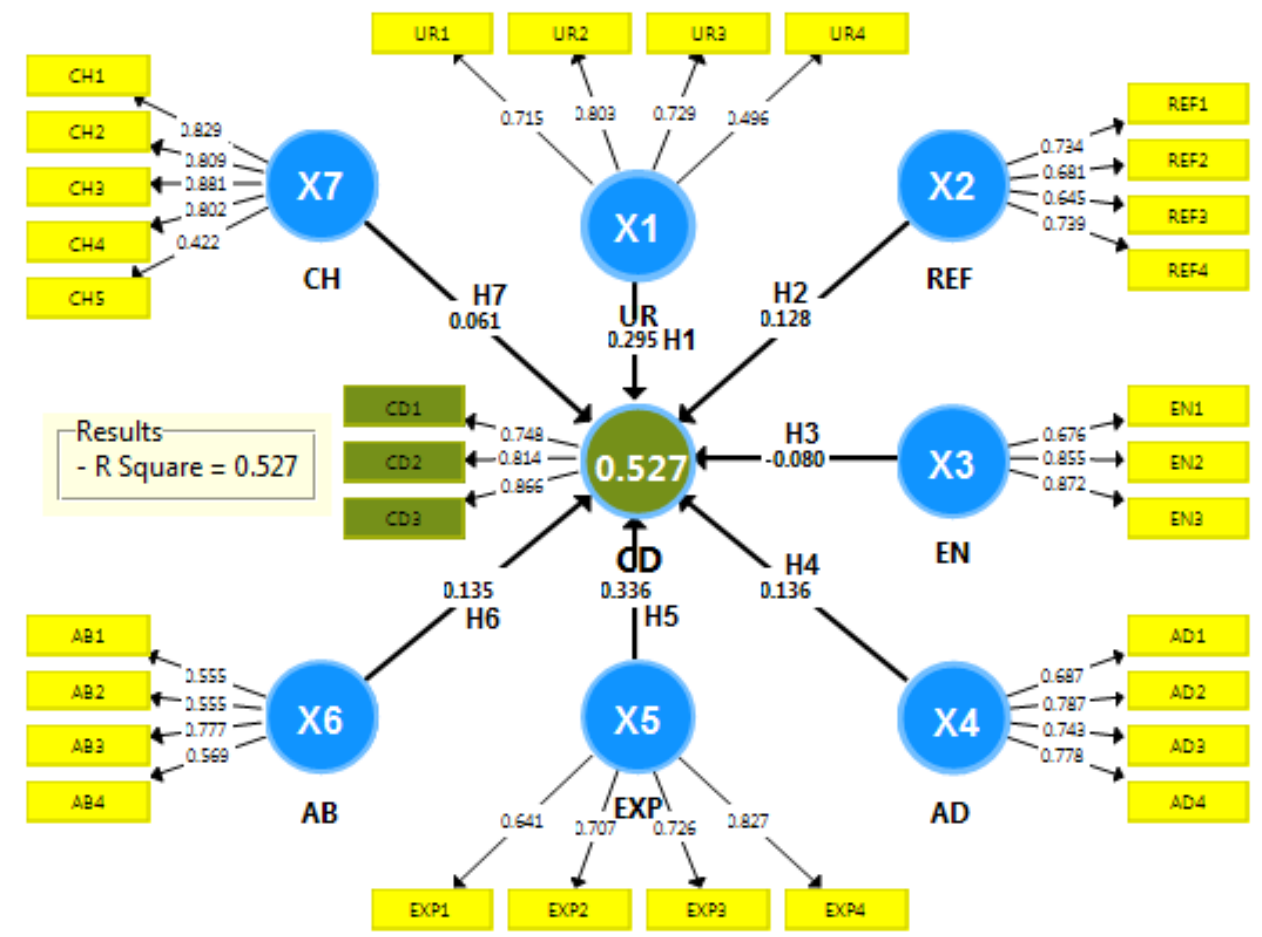

$\boldsymbol{U R}(X 1)$ : University Reputation, $\boldsymbol{R E F}(X 2):$ Reference (Family and Friend), $\boldsymbol{E N}(\mathrm{X} 3)$ : Enroll to university, $\boldsymbol{A D}(\mathrm{X} 4)$ : University Advertising, $\boldsymbol{E X P ( X 5 ) : ~ S t u d e n t ~ E x p e c t a t i o n , ~} \boldsymbol{A B}(\boldsymbol{X 6}):$ Student Ability, $\boldsymbol{C H}(\boldsymbol{X 7 )}):$ University Characteristics, $\boldsymbol{C D}(\mathbf{Y})$ : University Choice Decision

\section{Figure 2. The SEM model}

SEM results in figure 2 showed that the model was compatible with data research [15]. The university choice was affected by seven factors about $52.7 \%$.

In the SEM analysis in table 3, the variables that associated with university choice $(\mathrm{p}<0.05)$. The $\mathrm{AB}, \mathrm{CH}$ and EN aspects were not relative with university choice $(\mathbf{H 3}, \mathbf{H 6}, \mathbf{H 7})$ as table 3 (p>0.05). The most important factor for university choice was EXP aspects with the Beta equals to 0.336 . 
Table 3. Structural Equation Modeling (SEM)

\begin{tabular}{lccccc}
\multicolumn{1}{c}{ Hypotheses } & Beta & SE & T-value & P & Decision \\
AB -> CD (H6) & 0.135 & 0.073 & 1.853 & 0.064 & Unsupported \\
AD -> CD (H4) & 0.136 & 0.064 & 2.123 & 0.034 & Supported \\
CH -> CD (H7) & 0.061 & 0.057 & 1.083 & 0.279 & Unsupported \\
EN -> CD (H3) & -0.080 & 0.067 & 1.201 & 0.230 & Unsupported \\
EXP -> CD (H5) & 0.336 & 0.077 & 4.393 & 0.000 & Supported \\
REF -> CD (H2) & 0.128 & 0.060 & 2.136 & 0.033 & Supported \\
UR -> CD (H1) & 0.295 & 0.084 & 3.512 & 0.000 & Supported \\
\hline
\end{tabular}

$\operatorname{Beta}(r): S E=S Q R T(1-r 2) /(n-2) ; C R=(1-r) / S E ; P$-value $=T D I S T(C R, n-2,2)$

UR: University Reputation, $\boldsymbol{R E F}$ : Reference (Family and Friend), EN: Enroll to university, AD: University Advertising, EXP: Student Expectation, AB: Student Ability, CH: University Characteristics, CD: University Choice Decision

Table 4. Measurement of model SEM

\begin{tabular}{cccccc}
\hline SRMR & d_ULS & d_G1 & d_G2 & Chi-Square & NFI \\
0.083 & 3.435 & 1.090 & 0.894 & 777.069 & 0.576 \\
\hline
\end{tabular}

SEM results showed that the model was compatible with data research $[22,23]$ in table 3 and 4 . In bootstrapping, resampling methods were used to compute the significance of PLS coefficients. Output of significance levels can be retrieved from bootstrapping option. Table 3 shows the results of hypotheses testing; all the t values above 1.96 are significant at the 0.05 level. Hypotheses H1, H2, H4 and H5 were supported. Hypotheses H3, H6 and $\mathrm{H} 7$ were unsupported. The results indicated a positive and significant $(\mathrm{p}<0.05)$ association between university choice in table 3.

\section{CONCLUSION}

As the result of data analysis in results and discussion, four hypotheses were accepted. Hypotheses $\mathrm{H} 3$, H6 and H7 were unsupported. The study results had met the research objectives and supported the four hypotheses set out. Specifically, the results had confirmed the four components of the University Choice included University Advertising, Student Expectation, Reference (Family and Friend) and University Reputation. There were four components contribute significantly to the University Choice in order of importance: (1) Student Expectation, (2) University Reputation, (3) University Advertising and (4) Reference (Family and Friend). Student Ability, University Characteristics and Enroll to university were not influenced University Choice of Student.

\subsection{Implication}

From the perspective of marketers and practitioners, this study contributes to the understanding of a more complete list of critical factors for University Choice within the decision-making process of student. Through this deeper understanding, marketing practitioners can develop and improve their communication strategies. Such refinements could include the development of more targeted and engaging messages to encourage sharing of referral messages by students.

Within the context of education, this study provides recommendations for universities to gain advantage in a competitive landscape. Armed with a better understanding of how prospective students seek and evaluate to their use of choice factors and information-seeking behaviours, university managers and marketing practitioners can more effectively manage and plan for their institutions' marketing strategy. 
First, Student Expectation needs to be responsed: Job opportunities after graduation, soft skills, student's support to practice in large enterprises and creating students with full knowledge and experience in their field. This university should research firm's recruiting need, connect directly when students are studying to create job opportunities after graduation. This university should equip not only knowledge but also always register to participate in some technical and economic competitions between nationwide universities and communicating with the culture of neighboring countries. In addition, competitions need to be developed students' skills and the university reputation. This university should support students to practice in large enterprises. The university will establish clubs, courses on soft skills in behavioral skills, pre-crowd communication, basic computer skills, communication skills to create a foundation for students.

Second, University Reputation needs to be impoved: good prestige within the community, a wellrespected one, positively influencing value of learner's degree. There was cancelled observation because its loading was greater than 0.5 . The university is a good prestige within the community and quality training institution. It actively pays attention to maintaining key contents such as: practical teaching, real learning, prevention of achievement diseases, anti-negativity in examinations, building regulations. More rigorous examination, Building scientific working regulations to improve the effectiveness of school activities. It develops scientific working regulations to improve the effectiveness of its activities.

Third, University Advertising needs to be enhanced: Organizing orientation, meeting 12th grade students at high schools; quickly answering questions on website, fanpage, facebook; organizing tours, introducing for high school students and student support to enroll well.

Fourth, Reference (Family and Friend) includes: family, friend, teacher and consultant.

\subsection{Limitation}

Although the study was carefully designed and conducted, it also had some limitations. Participation in the survey was voluntary. Restriction on the research sample was selected by convenient data collection method at Industrial University of Ho Chi Minh City, Vietnam. Balanced samples should be expected in future research. The model only explained $52.7 \%$. The reason might be the small sample, it did not cover all fields of the university. Sample size needs to be increased. Respondents should be intended in many universities in Vietnam.

\section{Conflict of interest}

The authors declare that there are no conflicts of interest regarding the publication of this paper.

\section{Acknowledgements}

This work was supported in part by Industrial University of Ho Chi Minh City, Vietnam.

\section{REFERENCES}

[1] T. D. M. Le, "Word-of-mouth processing and higher education choice factors," School of Economics Finance and Marketing, RMIT University, College of Business, 2018.

[2] S. Husain, H. Safiei, A. Ghazali, N. N. M. Nazir, N. I. N. Redzuan, and F. A. Ghani, "Factors Affecting Students' Preferences Towards Private University College in Malaysia," Global Business and Management Research, vol. 10, p. 535, 2018.

[3] L. Iacopini and M. Hayden, "The Role of Parents in University Choice: Evidence from Vietnam," The Asia - Pacific Education Researcher, vol. 26, pp. 147-154, Aug 2017.

[4] D. Harahap, R. Hurriyati, V. Gaffar, and D. Amanah, "The impact of word of mouth and university reputation on student decision to study at university," Management Science Letters, vol. 8, pp. 649-658, 2018.

[5] A. P. Rachmadhani, N. U. Handayani, M. A. Wibowo, R. Purwaningsih, and H. Suliantoro, "Factor identification of higher education choice to enhance brand awareness of state university," in MATEC Web of Conferences, 2018, p. 01051.

[6] J. S. K. Ming, "Institutional factors influencing students' college choice decision in Malaysia: A conceptual framework," International Journal of Business and Social Science, vol. 1, 2010. 
[7] D. W. Chapman, "A model of student college choice," The Journal of Higher Education, vol. 52, pp. 490$505,1981$.

[8] K. Obermeit, "Students' choice of universities in Germany: structure, factors and information sources used," Journal of Marketing for Higher Education, vol. 22, pp. 206-230, 2012.

[9] C. Veloutsou, J. W. Lewis, and R. A. Paton, "University selection: information requirements and importance," International Journal of Educational Management, vol. 18, pp. 160-171, 2004.

[10] Y. J. Moogan, S. Baron, and K. Harris, "Decision-making behaviour of potential higher education students," Higher Education Quarterly, vol. 53, pp. 211-228, 1999.

[11] J. Hemsley-Brown and I. Oplatka, "University choice: what do we know, what don't we know and what do we still need to find out?," International Journal of Educational Management, vol. 29, pp. 254-274, 2015.

[12] J. C. Nunnally and I. Bernstein, "The assessment of reliability," Psychometric theory, vol. 3, pp. 248-292, 1994.

[13] N. T. Ngan and B. H. Khoi, "Empirical study on intention to use bike-sharing in Vietnam," IIOAB, vol. 10, pp. 1-6, 2019.

[14] B. H. Khoi and N. T. Ngan, "Factors impacting to smart city in Vietnam with smartpls 3.0 software application," IIOAB, vol. 10 pp. 1-8, 2019.

[15] K. K.-K. Wong, "Partial least squares structural equation modeling (PLS-SEM) techniques using SmartPLS," Marketing Bulletin, vol. 24, pp. 1-32, 2013.

[16] H. Latan and R. Noonan, Partial least squares path modeling: basic concepts, methodological issues and applications: Springer, 2017.

[17] B. H. Khoi and N. Van Tuan, "Using SmartPLS 3.0 to Analyse Internet Service Quality in Vietnam," in Studies in Computational Intelligence. vol. 760, ed: Springer, 2018, pp. 430-439.

[18] J. F. Hair, W. C. Black, B. J. Babin, R. E. Anderson, and R. L. Tatham, "Multivariate data analysis (Vol. 6)," ed: Upper Saddle River, NJ: Pearson Prentice Hall, 2006.

[19] J. F. Hair Jr, G. T. M. Hult, C. Ringle, and M. Sarstedt, A primer on partial least squares structural equation modeling (PLS-SEM): Sage Publications, 2016.

[20] B. H. Khoi, D. N. Dai, N. H. Lam, and N. Van Chuong, "The Relationship Among Education Service Quality, University Reputation and Behavioral Intention in Vietnam," in Studies in Computational Intelligence. vol. 809, ed: Springer, 2019, pp. 273-281.

[21] J. F. Hair, G. T. M. Hult, C. M. Ringle, M. Sarstedt, and K. O. Thiele, "Mirror, mirror on the wall: a comparative evaluation of composite-based structural equation modeling methods," Journal of the Academy of Marketing Science, pp. 1-17, 2017.

[22] J. Henseler, G. Hubona, and P. A. Ray, "Using PLS path modeling in new technology research: updated guidelines," Industrial management \& data systems, vol. 116, pp. 2-20, 2016.

[23] Hengky Latan and Richard Noonan, Partial Least Squares Path Modeling: Basic Concepts, Methodological Issues and Applications: Springer, 2017. 